\title{
Effects of The Leadership, Management And Governance Intervention On Maternal And Child Health Service Performances In Ethiopia: A Propensity Score Matched Analysis
}

Mesele Damte Argaw ( $\square$ mdamte5@gmail.com )

JSI Research \& Training Institute, Inc, Addis Ababa

Binyam Fekadu Desta

JSI Research \& Training Institute, Inc, Addis Ababa

Sualiha Abdlkader Muktar

JSI Research \& Training Institute, Inc, Addis Ababa

Wondwosen Shiferaw Abera

JSI Research \& Training Institute, Inc, Addis Ababa

Ismael Ali Beshir

JSI Research \& Training Institute, Inc, Addis Ababa

Israel Ataro Otoro

Federal Ministry of Health

Asegid Samuel

Federal Ministry of Health, Human Resource Development Directorate Addis Ababa

Deirdre Rogers

JSI Research \& Training Institute, Inc

Kristin Eifler

JSI Research \& Training Institute, Inc

\section{Research Article}

Keywords: Leadership, Management, and Governance, Performance improvement, Training, Ethiopia

Posted Date: June 2nd, 2021

DOI: https://doi.org/10.21203/rs.3.rs-534530/v1

License: @ (1) This work is licensed under a Creative Commons Attribution 4.0 International License. Read Full License 


\section{Abstract}

Background: The maternal, neonatal and child mortality rates in Ethiopia are among the reported highest in Africa. Despite the reported alarming mortality rates, there are proven public health interventions in place to avoid preventable maternal and child deaths. Leadership, management, and governance (LMG) interventions play a significant role in improving management systems, enhancing the work climate, and creating responsive health systems. Hence, the Ethiopian Ministry of Health with the support of the USAID Transform: Primary Health Care Activity has been implementing LMG interventions to improve performance of primary health care entities. The LMG interventions include a six-day classroom training with an additional six to nine months of leadership project implementation, supplemented with three to four onsite coaching sessions. The purpose of this evaluation was to measure the effects of LMG interventions on maternal and child health service performances and on the overall health system strengthening measurement results of primary health care entities.

Methods: The study used a cross-sectional study design with propensity matched score analysis and was conducted from August 28 , 2017, to September 30, 2018, in Amhara, Oromia, Tigray, and Southern Nations, Nationalities, and Peoples' (SNNP) regions. Data collection took place through interviewer and self-administered questionnaires among 227 LMG intervention exposed and 227 non-exposed health workers. Propensity score matched analysis was used to estimate the average treatment effects of LMG interventions on contraceptive acceptance rates, antenatal care, skilled birth attendance, postnatal care, full immunization services, growth monitoring services, management system, work climate and capacity to respond to new challenges.

Results: The mean overall maternal and child health key performance indicator score with standard deviation (SD) for the LMG intervention exposed group was $63.86 \pm 13.16$ (SD) and $57.02 \pm 13.71$ (SD) for the non-exposed group. The overall health system strengthening score for the LMG intervention exposed group (mean rank $=269.31$ ) and non-exposed group (mean rank $=158.69$ ) had statistically significant differences $(U=10.145, z=-11.175, p=0.001)$. The average treatment effects of 3.54, 3.51, 2.64, 3.00, 1.073.34 percentage-points were observed for contraceptive acceptance rate, antenatal care, skilled birth attendance, postnatal care, full immunization, and growth monitoring services, respectively. In addition, with regards to health system strengthening measurements, we found an average treatment effect (ATE) of $12.46,4.79$ and 4.88 percentage points for strengthening management system, enhancing work climate and capacity to respond to new challenges, respectively.

Conclusion: We found positive evidence of effects of the LMG intervention on increased maternal and child health services performances at primary healthcare entities. Moreover, health facilities with LMG intervention exposed health workers had a higher and statistically significant difference in management systems, work climate and readiness to face new challenges. Therefore, this study generates evidence for integrating LMG interventions to improve the performance of primary healthcare entities and maternal and child service uptake of community members, which contributes to the reduction maternal and child deaths.

\section{Introduction}

Within the last couple of decades, evidence shows global improved health outcomes. However, this remarkable success significantly varies from place to place. In particular, the health systems of sub-Sahara Africa regions still show low levels of access to essential quality health services at an affordable costs $[1,2,3]$. Despite the reported substantial reductions in maternal and neonatal mortality rates, the region is still registering the highest rates throughout the world. The causes for this are complex and multifaceted and can be explained with determinants related to communities, health workforces, as well as the health and economic systems of countries. The World Health Organization (WHO) recommends applying an interlinked six building block approach to strengthen health systems [1]. Capacitating the leadership, management, and governance competencies of health workforces at all levels is believed to improve the organizational culture and achievements of proven public health interventions $[1,2,3]$.

Ethiopia's health system, as in many other low-income countries, lacks adequate infrastructure and resources. Health managers often lack the leadership, management, and governance (LMG) competencies and skills to overcome the numerous challenges associated with delivering proven, cost-effective health services, such as family planning, quality of care along the childbirth continuum, and childcare [2, 3 , 8]. The country's maternal and newborn health still needs improvement, with significant disparities in access to services and health outcomes. Although the proportion of mothers dying per 100,000 live births declined from 1,400 in 1990 to 420 in 2013, the ratio is still unacceptably high [9]. Similarly, the infant mortality rate has declined from 59.6 per 1,000 live births in 2009 to 36.5 per 1,000 live births in 2019 [10].

Some studies have shown that the bottlenecks in the performance of health systems can be solved by building competencies of health workers related to leading, managing and governing practices [3, 6, 11-15]. Therefore, Ethiopia has adopted and implemented LMG interventions to strengthen its health system and build services that are accessible to more people by developing inspired and inspiring 
leaders, establishing sound management systems, and ensuring transparent practices within and among individuals, networks, organizations, and governmental bodies.

However, to the knowledge of the investigators of this study, there are no studies which determine effects of the LMG intervention on maternal and child health service performance using propensity score matching analysis. Therefore, the aim of this study was to determine the effects of leadership, management and governance interventions on maternal and child health service performance at primary healthcare entities after implementing the intervention over the course of a one-year period.

\section{Materials And Methods}

\subsection{Study design}

This study employed a cross sectional study design with propensity matched score analysis that measures the effects of the LMG intervention on maternal and child health service performance by LMG exposure status [16-18]. The propensity score matching (PSM) approach was used to explain possible differences at baseline variables between LMG exposed and non-exposed groups. The PSM aims to balance the LMG intervention exposed and non- exposed groups with respect to measured baseline covariates, to achieve a comparison with reduced selection bias [19-21]. Hence, any observed differences on maternal and child health service coverages can demonstrate the effect of the LMG intervention. The study was conducted between August 28, 2017 and September 30, 2018, in Amhara, Oromia, SNNP, and Tigray regions of Ethiopia.

\subsection{Study setting}

The Ethiopian health system is comprised of primary, secondary and tertiary levels. The primary level of the health tier system encompasses a district hospital which covers $60,000-100,000$ people and four to five health centers with an average targeted population of 25,000 people. In addition, each health center has five satellite health posts with a target population of 3,500 to 5,000 people. The primary healthcare entities are mandated to provide preventive, curative, promotive and rehabilitative health services to about 100,000 people. The secondary and tertiary levels manage complex heath conditions for larger size populations and include general and referral hospitals [4].

USAID Transform: Primary Health Care works closely with regional state health bureaus and aims to contribute to the successful achievement of the national goal of preventing child and maternal deaths (PCMD). Towards this aim, the Activity has implemented LMG development interventions to create a conducive work environment, strengthen management systems, create responsive healthcare providers and improve their capacity towards resource mobilization, allocation and utilization [7].

\section{Description of the LMG intervention}

The LMG intervention includes a formal six-day basic training package, with subsequent exercises for six to nine months against developed performance improvement projects to capacitate staff at primary healthcare entities. LMG trained healthcare providers were coached for three to four session by experts. The intervention is designed to institutionalize inspired and inspiring leadership, sound management, as well as consistent, and transparent governance [22] (Additional file 1). A successful completion of the intervention earns 78 continuing education units (CEUs) for each participant [22].

Based on the national course syllabus, trainees are informed about priority health areas, and concept of leadership, management and governance for a result model of performance improvement. During the classroom trainings, the LMG core teams develop performance improvement projects using a tool named the 'challenge model' [5]. This tool helps the core LMG teams identify their organizational challenges through reviewing their organizational mission and strategic priorities; develop a shared vision for the future that contributes to the accomplishment of the organizational mission or strategic priorities; define one measurable result that can be achieved in a short amount of time; assess their current situation to take an accurate baseline measurement; identify obstacles and root causes using a fishbone analysis, the why technique or workflow analysis which helps the core LMG teams reach the stated desired result; define challenges in light of the root causes and select priority actions; develop an action plan that estimates the human, material and financial resources needed and timeline for implementing the actions; and implement the plan and monitor and evaluate progress towards achieving the desired results $[5,22]$.

The LMG trained and exposed health workers then organized staff meetings to go through the components of the challenge model within their respective workplaces. The performance improvement projects which involve the buy-in by all inspired staff were implemented for six to nine months, during the implementation period and each team received three or four on-site coaching sessions [22]. The intended 
outcomes of the performance improvement projects included developing the leading, managing, and governing competencies of health workers at all levels and building services which are accessible for more people in communities. Some of the performance improvement projects aimed to increase the proportion of institutional deliveries, the proportion of modern contraceptive users, and proportion of wellbaby service utilization (Additional file 2).

The performance improvement projects also helped trainees use LMG training concepts to identify and solve challenges at their workplace. After implementation, each performance improvement project team was assessed against their intended targets. From 25th December 2017 to 30th March 2018, the assessment team, comprised of LMG experts from participating in-service training institutions, zonal health departments, and the USAID Transform: Primary Health Care Activity, appraised the performances of LMG intervention exposed health workers and helped them to present findings and results at organized knowledge sharing events. In four years (2017-2019), through the direct support of the Activity, 184 districts and 519 health centers had LMG trained healthcare workers [7]. The trainees developed 656 performance improvement projects and implemented them in their respective primary healthcare entities [23].

\subsection{Target population}

Two groups of the population were targeted, namely: LMG intervention exposed and non-exposed health workers employed in the four regions of Ethiopia and primary healthcare entities providing maternal and child health services.

\subsection{Eligibility criteria}

Health workers who volunteered to participate and that were working within the USAID Transform: Primary Health Care Activity's targeted primary healthcare entities were enrolled in this study.

\subsection{Sampling size and sampling}

The national average performance scores against selected maternal and child health indicators of primary healthcare entities were found to be at $65 \%$ [24]. With the assumption of training directives, LMG trained and capacitated healthcare workers improved the score of primary healthcare entities to $80 \%$ or more on the same key performance indicators (KPIs), and believing the presence of heterogeneity across regions and between primary healthcare entities, design effect of 2 is considered $[25,26]$. The required sample size with a power of $90 \%$ to detect the effects of the LMG intervention for exposed $\left(n_{1}=272\right)$ and non- exposed $\left(n_{2}=272\right)$ group will be 544 .

\subsection{Data collection}

The questionnaires were prepared after a thorough review of relevant literature and the national leadership, management, and governance in-service training materials for hospitals and health center managers $[3,22,27]$. The questionnaires were developed in English (Additional file 3) and translated into local languages (i.e., Amharic, Afan Oromo, and Tigrigna), then translated back into English. The data were collected from LMG intervention exposed and non-exposed healthcare providers using interviewer administered and self-administered structured questionnaires. Sixteen data collectors, each with clinical, health management, social science, or public health training were recruited. Data collectors and supervisors were trained on ethical principles, data collection tools, and interviewing techniques. Before the actual data collection began, all tools were piloted and amended accordingly.

\section{Outcome measurements}

In this study, six maternal and child health key performance indicators which are endorsed by the Ministry of Health [24] and three categories of immediate outcomes on leading, managing and governing model for results measurements were considered [5, 22]. The detailed characteristics of selected KPIs are discussed after which the features of the health systems strengthening variables will be presented.

\subsubsection{Maternal and child health performance}

Data were extracted from the health facility routine health information management systems. Six maternal and child health program performance KPIs were selected as a dependent variable. The indicators were: (1) contraceptive acceptance rate (CAR); (2) antenatal care (ANC); (3) skilled (institutional) birth attendance (SBA); (4) postnatal care (PNC); (5) full immunization coverage for infants under the age of 1; and (6) growth monitoring for children 2-59 months old. Each indicator was reported from 0 to 100 percentage. The average of all six indicators was considered as an overall maternal and child health performance score.

\subsubsection{Health system strengthening survey}


Eighteen questions with a 10-point Likert scale [28] were used to measure responses to statements presented on: strengthened management systems (9 items); enhanced work climate (5 items); and responsiveness or capacity of the health system to overcome new challenges ( 4 items). The sample questionnaire for each category is presented in box 1 . The respondents were LMG intervention exposed and non-exposed health workers operating within the primary healthcare entities.

\section{Box 1: Sample questionnaires}

\begin{tabular}{|lll|}
\hline $\begin{array}{l}\text { Serial } \\
\text { no. }\end{array}$ & Sample tool & Category \\
\hline WC1 & $\begin{array}{l}\text { In this office, employees understand the organizational structure and reporting lines of } \\
\text { their unit/department and how their job functions relate to overall departmental } \\
\text { objectives and goals. }\end{array}$ & $\begin{array}{l}\text { Strengthened management } \\
\text { systems. }\end{array}$ \\
\hline WC10 & My contributions at work are acknowledged and appreciated. & Enhanced work climate. \\
\hline WC13 & $\begin{array}{l}\text { In this office, supervisors delegate challenging assignments to assistants, which helps } \\
\text { them to develop their skills and expertise. }\end{array}$ & $\begin{array}{l}\text { Responsiveness or capacity of } \\
\text { health system to overcome new } \\
\text { challenges. }\end{array}$ \\
\hline
\end{tabular}

\section{Independent variables}

Data on possible independent variables were collected. Individual characteristics of the study participants which includes age, gender, profession, educational level, service years and salary were captured. In addition, primary healthcare entity characteristics such as access to roads, distance from zone capital in kilometers, and catchment population were collected.

\subsection{Data analysis}

The data were analyzed using the Statistical Package for Social Sciences (SPSS) version 25 [29]. A PSM analysis was conducted using Rplugin for propensity score matching for SPSS [30]. ATEs were determined using STATA 13 [31]. The internal reliability of the tools was assessed using Cronbach's alpha values [32]. According to Bland et al., (1997), if the Cronbach's alpha value score is more than 0.7, the scale can be considered reliable [33]. The tools have 18 questions divided into three categories, namely: strengthened management systems (9 questions), enhanced work climate (5 questions), and the capacity to respond to changes (4 questions). The reliability test results were 0.839 for work climate, 0.895 for strengthened management systems, and 0.886 for the capacity to respond to changes, which showed the scale used was internally consistent and reliable.

A statistical test using multi-collinearity analysis through determining the variance inflation factor (VIF) was run to check the tools' divergent validity [17]. According to Menard (1995), if the VIF reported value exceeds 10, it implies the associated regression coefficients are poorly estimated because of multi-collinearity [34]. In this study, the collinearity test VIF results were: 1.018 for work climate, 2.94 for strengthened management systems, and 6.443 for capacity to respond to new challenges and no VIF value exceeded 10 . Hence, there was no observed serious multi-collinearity affecting the regression coefficient.

PSM is a single score used to balance the LMG intervention exposed and non-exposed groups on observed covariates [30]. In this study, the covariates included in the PSM model are socio-demographic characteristic of health workers, and targeted primary healthcare entities i.e. catchment population, distance from zone capital in kilometers, and access to all weather roads. During matching, a standardized difference of covariates between the two groups with less than 10\% was taken as adequate. Using a logistics regression estimation (logit model) the PSM was analyzed by assigning 1 for LMG intervention exposed and 0 for non-exposed groups, with nearest neighbor matching, caliper of 0.2 and matching ratio of 1 to 1.The relative multivariate imbalance L1 was 0.926 before matching and 0.916 after matching [35]. Only place of work had a large imbalance after PSM with $|d|=0.80$, which violates the recommended criteria standard error difference of $|\mathrm{d}|<0.25$ (Additional file 4).

Finally, using PSM, 454 participants data that were collected from 227 LMG intervention exposed and 227 non-exposed groups. Descriptive statistics were employed using frequencies and tables. The homogeneity of the data was checked using Levene's test for equality of variances. The results revealed that maternal and child health coverage data were found to be homogeneous at $p>0.05$. While the data on strengthening management system, enhanced work climate, and capacity to respond to new challenges were found to be nonhomogeneous at $\mathrm{p}<0.05$ (Additional file 5).

An independent sample t-test was analyzed to check statistical difference on maternal and child health service performance coverage between LMG intervention exposed and non-exposed groups. In addition, a non-parametric test, (Mann-Whitney U Test) was conducted to check presence of significant differences in mean rank LMG intervention exposed and non-exposed groups. Finally, ATEs on selected

Page 5/13 
maternal and child health key performance indicators and health systems strengthening measurements by LMG exposure status were determined with associated 95\% confidence interval (CI) [31].

\subsection{Ethical considerations}

Ethical clearance was obtained from four regional institutional review boards. Ethical clearances were granted by the Amhara Public Health Institute, (Ref No. HRTT02/137/2018), the Oromia Regional State Health Bureau, (Ref No. BEFO/HBTPH/1-8/476), the SNNP Regional State Health Bureau, (Ref No. PLMG-19/8407), and the Tigray Regional State Health Bureau's (Ref No. 453/1418/10) institution review boards and research ethics committees. Data were collected after getting full informed written consent from each participant and facility manager. Privacy, anonymity, and confidentiality were maintained throughout the data collection, analysis, and report writing activities. This study had no known risk and no payment was made to participants.

\section{Results}

Table 1 presents the background socio-demographic characteristics of the study participants categorized by LMG exposure, before and after propensity score matched analysis. A total of 544 primary healthcare entities that have 272 LMG intervention exposed and 272 nonexposed groups were enrolled in this study. However, after PSM, only data from 454 primary healthcare entities were included in the final analysis The data analysis revealed that before PSM there were significant differences on distribution of age categories ( $p<0.002)$, place of work $(p<0.001)$ and years of services $(p<0.001)$ tenured by the study participants. While after PSM analysis only the distribution of place of work was found statically different at $p<0.001$. 
Table 1

Socio-demographic characteristics of the study participants by LMG exposure and PSM, September 2018

\begin{tabular}{|c|c|c|c|c|c|c|c|c|c|c|c|c|c|c|c|}
\hline \multirow[t]{3}{*}{ Variable } & \multirow[t]{3}{*}{ Category } & \multicolumn{5}{|c|}{$\begin{array}{l}\text { Before propensity score matching } \\
\text { LMG interventions }\end{array}$} & \multirow{2}{*}{\multicolumn{2}{|c|}{$\begin{array}{l}\text { Total }(N= \\
544)\end{array}$}} & \multicolumn{5}{|c|}{$\begin{array}{l}\text { After propensity score matching } \\
\text { LMG interventions }\end{array}$} & \multirow{2}{*}{\multicolumn{2}{|c|}{$\begin{array}{l}\text { Total }(\mathrm{N}= \\
\text { 454) }\end{array}$}} \\
\hline & & \multicolumn{2}{|c|}{$\begin{array}{l}\text { Exposed } \\
(N=272)\end{array}$} & \multicolumn{2}{|c|}{$\begin{array}{l}\text { Non } \\
\text { exposed } \\
(\mathbb{N}=272)\end{array}$} & \multirow[t]{2}{*}{$\begin{array}{l}p- \\
\text { value }\end{array}$} & & & \multicolumn{2}{|c|}{$\begin{array}{l}\text { Exposed } \\
(\mathbf{N}=227)\end{array}$} & \multicolumn{2}{|c|}{$\begin{array}{l}\text { Non- } \\
\text { exposed } \\
(\mathbb{N}=227)\end{array}$} & \multirow[t]{2}{*}{$\begin{array}{l}p- \\
\text { value }\end{array}$} & & \\
\hline & & $\mathrm{N}$ & $\%$ & $\mathrm{~N}$ & $\%$ & & $\mathrm{~N}$ & $\%$ & $\mathrm{~N}$ & $\%$ & $\mathrm{~N}$ & $\%$ & & $\mathrm{~N}$ & $\%$ \\
\hline \multirow[t]{4}{*}{ Region } & Amhara & 80 & $29 \%$ & 71 & $26 \%$ & 0.736 & 151 & $28 \%$ & 59 & $26 \%$ & 59 & $26 \%$ & 0.324 & 118 & $26 \%$ \\
\hline & Oromia & 75 & $28 \%$ & 77 & $28 \%$ & & 152 & $28 \%$ & 68 & $30 \%$ & 67 & $30 \%$ & & 135 & $30 \%$ \\
\hline & SNNP & 83 & $31 \%$ & 93 & $34 \%$ & & 176 & $32 \%$ & 69 & $30 \%$ & 81 & $36 \%$ & & 150 & $33 \%$ \\
\hline & Tigray & 34 & $13 \%$ & 31 & $11 \%$ & & 65 & $12 \%$ & 31 & $14 \%$ & 20 & $9 \%$ & & 50 & $11 \%$ \\
\hline \multirow[t]{2}{*}{ Sex } & Male & 201 & $74 \%$ & 202 & $74 \%$ & 0.922 & 403 & $74 \%$ & 168 & $74 \%$ & 171 & $75 \%$ & 0.922 & 339 & $75 \%$ \\
\hline & Female & 71 & $26 \%$ & 70 & $26 \%$ & & 141 & $26 \%$ & 59 & $26 \%$ & 56 & $25 \%$ & & 115 & $25 \%$ \\
\hline \multirow[t]{4}{*}{ Age } & $<30$ years & 171 & $63 \%$ & 209 & $77 \%$ & 0.002 & 380 & $70 \%$ & 163 & $72 \%$ & 176 & $78 \%$ & 0.367 & 339 & $75 \%$ \\
\hline & $31-40$ years & 74 & $27 \%$ & 46 & $17 \%$ & & 120 & $22 \%$ & 56 & $25 \%$ & 44 & $19 \%$ & & 100 & $22 \%$ \\
\hline & $41-50$ years & 16 & $6 \%$ & 14 & $5 \%$ & & 30 & $6 \%$ & 8 & $4 \%$ & 7 & $3 \%$ & & 15 & $3 \%$ \\
\hline & $51+$ years & 11 & $4 \%$ & 3 & $1 \%$ & & 14 & $3 \%$ & & & & & & & \\
\hline \multirow[t]{6}{*}{ Profession } & BSc nurse & 34 & $13 \%$ & 38 & $14 \%$ & 0.767 & 72 & $13 \%$ & 28 & $12 \%$ & 26 & $11 \%$ & 0.997 & 54 & $12 \%$ \\
\hline & $\begin{array}{l}\text { BSc public } \\
\text { health officer }\end{array}$ & 68 & $25 \%$ & 55 & $20 \%$ & & 123 & $23 \%$ & 46 & $20 \%$ & 45 & $20 \%$ & & 91 & $20 \%$ \\
\hline & $\begin{array}{l}\text { Diploma } \\
\text { nurse }\end{array}$ & 121 & $44 \%$ & 122 & $45 \%$ & & 243 & $45 \%$ & 109 & $48 \%$ & 108 & $48 \%$ & & 217 & $48 \%$ \\
\hline & $\begin{array}{l}\text { Midwife (BSc } \\
\text { and } \\
\text { diploma) }\end{array}$ & 23 & $8 \%$ & 30 & $11 \%$ & & 53 & $10 \%$ & 23 & $10 \%$ & 25 & $11 \%$ & & 48 & $11 \%$ \\
\hline & $\begin{array}{l}\text { MSc health } \\
\text { services } \\
\text { management }\end{array}$ & 12 & $4 \%$ & 13 & $5 \%$ & & 25 & $5 \%$ & 9 & $4 \%$ & 9 & $4 \%$ & & 18 & $4 \%$ \\
\hline & Other & 14 & $5 \%$ & 14 & $5 \%$ & & 28 & $5 \%$ & 12 & $5 \%$ & 14 & $6 \%$ & & 26 & $6 \%$ \\
\hline \multirow[t]{3}{*}{ Salary } & $<3,500$ ETB $^{*}$ & 77 & $28 \%$ & 91 & $33 \%$ & 0.331 & 168 & $31 \%$ & 72 & $32 \%$ & 76 & $33 \%$ & 0.662 & 148 & $33 \%$ \\
\hline & $\begin{array}{l}3,501-8,540 \\
\text { ETB }\end{array}$ & 164 & $60 \%$ & 157 & $58 \%$ & & 321 & $59 \%$ & 135 & $59 \%$ & 136 & $60 \%$ & & 271 & $60 \%$ \\
\hline & $8541+$ ETB & 31 & $11 \%$ & 24 & $9 \%$ & & 55 & $10 \%$ & 20 & $9 \%$ & 15 & $7 \%$ & & 35 & $8 \%$ \\
\hline \multirow{3}{*}{$\begin{array}{l}\text { Marital } \\
\text { status }\end{array}$} & Single & 89 & $33 \%$ & 95 & $35 \%$ & 0.425 & 184 & $34 \%$ & 78 & $34 \%$ & 83 & $37 \%$ & & 161 & $35 \%$ \\
\hline & Married & 181 & $67 \%$ & 172 & $63 \%$ & & 353 & $65 \%$ & 147 & $65 \%$ & 141 & $62 \%$ & & 288 & $63 \%$ \\
\hline & Separated & 2 & $1 \%$ & 5 & $2 \%$ & & 7 & $1 \%$ & 2 & $1 \%$ & 3 & $1 \%$ & & 5 & $1 \%$ \\
\hline \multirow{3}{*}{$\begin{array}{l}\text { Years of } \\
\text { service }\end{array}$} & $<5$ years & 134 & $49 \%$ & 158 & $58 \%$ & 0.001 & 292 & $54 \%$ & 118 & $52 \%$ & 131 & $58 \%$ & 0.220 & 249 & $55 \%$ \\
\hline & $6-21$ years & 138 & $51 \%$ & 104 & $38 \%$ & & 142 & $26 \%$ & 109 & $48 \%$ & 96 & $42 \%$ & & 205 & $45 \%$ \\
\hline & $22+$ years & 0 & $0 \%$ & 10 & $4 \%$ & & 10 & $2 \%$ & & & & & & & \\
\hline
\end{tabular}

\section{Effect of LMG intervention}

An independent sample t-test was analyzed with seven variables after confirming the assumption of homogeneousness of the data set using Levene's test ( $p>0.05$ ). The mean overall maternal and child health KPIs score was $63.86 \pm 13.16$ standard deviation (SD) and 57.02 \pm 13.71 SD among LMG intervention exposed and non-exposed groups, respectively. The performance score was significantly higher 
among the LMG intervention exposed group than the non-exposed group with $t=5.43, \mathrm{df}=452, p<0.001$. The difference of 6.84 percentage-points in the average maternal and child health KPIs had a statistically significant difference between the LMG intervention exposed and non-exposed groups (Table 2).

Table 2: Maternal and child health service KPI scores by LMG exposure status using an independent samples test, 2018

\begin{tabular}{|c|c|c|c|c|c|c|c|c|c|c|c|}
\hline & \multicolumn{11}{|c|}{ t-test for Equality of Means } \\
\hline & \multicolumn{2}{|c|}{$\begin{array}{l}\text { LMG exposed } \\
\mathrm{N}=227\end{array}$} & \multicolumn{2}{|c|}{$\begin{array}{l}\text { Non-LMG } \\
\text { exposed } \\
\mathrm{N}=227\end{array}$} & \multirow[t]{2}{*}{$\mathrm{T}$} & \multirow[t]{2}{*}{ df } & \multirow[t]{2}{*}{$\begin{array}{l}\text { Sig. } \\
\text { (2- } \\
\text { tailed) }\end{array}$} & \multirow[t]{2}{*}{$\begin{array}{l}\text { Mean } \\
\text { difference }\end{array}$} & \multirow[t]{2}{*}{$\begin{array}{l}\text { Std. error } \\
\text { difference }\end{array}$} & \multicolumn{2}{|c|}{$\begin{array}{l}95 \% \text { confidence } \\
\text { interval of the } \\
\text { difference }\end{array}$} \\
\hline & Mean & SD & Mean & SD & & & & & & Lower & Upper \\
\hline $\begin{array}{l}\text { Contraceptive } \\
\text { acceptance rate (CAR) }\end{array}$ & 82.47 & 16.59 & 75.96 & 16.38 & 4.21 & 452 & 0.001 & 6.50 & 1.55 & 3.47 & 9.55 \\
\hline Antenatal care (ANC) & 69.75 & 26,37 & 60.65 & 24.64 & 3.79 & 452 & 0.001 & 9.09 & 2.39 & 4.39 & 13.81 \\
\hline $\begin{array}{l}\text { Skilled birth attendance } \\
\text { (SBA) }\end{array}$ & 56.28 & 22.97 & 46.39 & 22.26 & 4.66 & 452 & 0.020 & 9.89 & 2.12 & 5.72 & 14.06 \\
\hline Postnatal care (PNC) & 64.42 & 22.2 & 56.12 & 21.92 & 4.01 & 452 & 0.011 & 8.30 & 2.07 & 4.23 & 12.37 \\
\hline Full immunization (FI) & 80.41 & 15.12 & 78.00 & 15.31 & 1.69 & 452 & 0.093 & 2.40 & 1.43 & -0.40 & 5.22 \\
\hline $\begin{array}{l}\text { Growth monitoring } \\
\text { (GM) }\end{array}$ & 37.83 & 23.42 & 24.98 & 23.48 & 3.56 & 452 & 0.678 & 7.84 & 2.20 & 3.52 & 12.17 \\
\hline Overall KPI score & 63.86 & 13.16 & 57.02 & 13.71 & 5.43 & 452 & 0.001 & 6.84 & 1.26 & 4.36 & 9.32 \\
\hline
\end{tabular}

Four variables were found non-homogeneous on Levene's test $(P<0.05)$ and a non-parametric independent samples Mann-Whitney $U$ test was applied to check differences in performance of primary healthcare entity scores between LMG intervention exposed and non- exposed groups. The results revealed that the overall work climate scores for LMG intervention exposed (mean rank $=296.31$ ) and non- exposed (mean rank $=158.69$ ) were statistically significant different, $U=10,145, Z=-11.175, p=0.001$ (Table 3).

Table 3

Health systems strengthening mean rank test using Mann-Whitney U Test, 2018

\begin{tabular}{|c|c|c|c|c|c|c|c|c|}
\hline & \multicolumn{2}{|c|}{$\begin{array}{l}\text { Strengthen management } \\
\text { system (A) }\end{array}$} & \multicolumn{2}{|c|}{$\begin{array}{l}\text { Enhanced work } \\
\text { climate (B) }\end{array}$} & \multicolumn{2}{|c|}{$\begin{array}{l}\text { Capacity to respond to new } \\
\text { challenges (C) }\end{array}$} & \multicolumn{2}{|c|}{$\begin{array}{l}\text { Overall work climate } \\
\text { score } \\
(A)+(B)+(C)\end{array}$} \\
\hline & $\begin{array}{l}\text { LMG } \\
\text { exposed }\end{array}$ & $\begin{array}{l}\text { Non- } \\
\text { exposed }\end{array}$ & $\begin{array}{l}\text { LMG } \\
\text { exposed }\end{array}$ & $\begin{array}{l}\text { Non- } \\
\text { exposed }\end{array}$ & LMG exposed & Non- exposed & $\begin{array}{l}\text { LMG } \\
\text { exposed }\end{array}$ & $\begin{array}{l}\text { Non- } \\
\text { exposed }\end{array}$ \\
\hline$N$ & 227 & 227 & 227 & 227 & 227 & 227 & 227 & 227 \\
\hline Mean rank & 312.71 & 142.29 & 259.52 & 195.48 & 263.99 & 191.01 & 296.31 & 158.69 \\
\hline Sum of ranks & 70984.50 & 32300.50 & 58911.50 & 44373.50 & 59925.50 & 43359.50 & 67262.00 & 36023.00 \\
\hline $\begin{array}{l}\text { Mann-Whitney } \\
\text { U }\end{array}$ & 6422.500 & & 18495.500 & & 17481.500 & & 10145.000 & \\
\hline Wilcoxon W & 32300.500 & & 44373.500 & & 43359.500 & & 36023.000 & \\
\hline Z & -13.840 & & -5.220 & & -5.929 & & -11.175 & \\
\hline $\begin{array}{l}\text { Asymp. sig. (2- } \\
\text { tailed) }\end{array}$ & .001 & & .001 & & .001 & & .001 & \\
\hline
\end{tabular}

Average treatment effects (ATEs)

ATEs were analyzed on maternal and child health service performance coverages against LMG intervention exposure status of primary healthcare entities. Exposure to LMG interventions had a statistically significant association $(p<0.05)$ with higher contraceptive acceptance rate $(z=3.54, p=0.001)$, antenatal care $(z=3.51, p=0.001)$, skilled birth attendance $(z=2.64, p=0.008)$, postnatal care $(z=$ 
3.00, $p=0.003)$, growth monitoring $(z=3.34, p=0.001)$, and overall work climate scores $(z=4.34, p=0.001)$. The highest ATE of the LMG intervention exposure was found in ANC service performance coverage, followed by skilled birth attendance. In contrast, the effects for under-1 full immunization coverage was not statistically different by LMG exposure at $(z=1.07, p=0.285)(T a b l e ~ 4)$.

Table 4

Maternal and child health service KPIs and health system strengthening scores with average treatment effects, 2018

\begin{tabular}{|c|c|c|c|c|c|c|}
\hline \multirow{3}{*}{$\begin{array}{l}\text { Variable } \\
\\
\begin{array}{l}\text { Contraceptive acceptance } \\
\text { rate }\end{array}\end{array}$} & \multirow{3}{*}{$\begin{array}{l}\text { Coef. } \\
6.40\end{array}$} & \multirow{3}{*}{$\begin{array}{l}\begin{array}{l}\text { Al } \\
\text { robust }\end{array} \\
\begin{array}{l}\text { Std. } \\
\text { err }\end{array} \\
1.81\end{array}$} & \multirow{3}{*}{$\begin{array}{l}\mathbf{z} \\
3.54\end{array}$} & \multirow{3}{*}{$\begin{array}{l}P>|z| \\
0.001\end{array}$} & \multicolumn{2}{|c|}{ [95\% conf. interval] } \\
\hline & & & & & & \\
\hline & & & & & 2.85 & 9.95 \\
\hline Antenatal care & 9.98 & 2.84 & 3.51 & 0.001 & 4.41 & 15.55 \\
\hline Skilled birth attendance & 7.89 & 2.98 & 2.64 & 0.008 & 2.04 & 13.74 \\
\hline Postnatal care & 7.49 & 2.49 & 3.00 & 0.003 & 2.60 & 12.39 \\
\hline Full immunization & 1.92 & 1.79 & 1.07 & 0.285 & -1.60 & 5.44 \\
\hline Growth monitoring & 7.57 & 2.27 & 3.34 & 0.001 & 3.12 & 12.01 \\
\hline Overall KPI performance & 6.37 & 1.46 & 4.35 & 0.001 & 3.50 & 9.25 \\
\hline $\begin{array}{l}\text { Strengthened } \\
\text { management system }\end{array}$ & 2.35 & .19 & 12.46 & 0.001 & 1.98 & 2.72 \\
\hline Enhanced work climate & 1.11 & .23 & 4.79 & 0.001 & .66 & 1.56 \\
\hline $\begin{array}{l}\text { Capacity to respond to } \\
\text { new challenges }\end{array}$ & .96 & .19 & 4.88 & 0.001 & .58 & 1.35 \\
\hline Overall work climate & 1.71 & .18 & 9.32 & 0.001 & 1.35 & 2.08 \\
\hline
\end{tabular}

\section{Discussion}

This PSM study was conducted to evaluate the effects of the USAID Transform: Primary Health Care Activity supported LMG intervention, on maternal and child health service performance in Ethiopia. The results of this study generate evidences for policy makers, development partners, and health workers to strategize and adapt proven interventions to improve access to and quality for maternal and child health services, enhance work climates and prepare health workers to face new challenges at primary healthcare facilities [5, 22].

In this study, we found a significant positive gain in maternal and child health service KPI scores. More specifically, the LMG intervention had a positive association with contraceptive acceptance rate, skilled birth attendance, postnatal care, and growth monitoring service coverages. Hence, the multi-faceted LMG intervention addresses some of the gaps in desired competencies and skills of health workers which enables them to solve exiting challenges in their workplace. These findings were consistent with other similar studies documented with significant increases with health service coverage as a result of LMG training and interventions in Zambia, Gambia, Egypt, Ethiopia, Ghana, Kenya and Mozambique [3, 6, 11-15, 36, 37].

Overall, the LMG intervention increased the maternal and child health KPIs by $4.35 \%$. This gain is achieved as a result of viable, committed and motivated health workers, inspired and inspiring leadership, and effective and efficient use of resources. Additional efforts through documentation, sharing vision or mission among all staff, enhanced organizing and aligning resource capacities, motivation of staff, also contribute to positive results. Desta et al., (2020) documented that LMG intervention districts were better at capacitating health workers, strengthening teams, and availing inputs than non-LMG intervention districts [37]. Similarly, La Rue et al., (2012), confirm that health service coverages were better in intervention districts than comparison districts through strengthening of leadership and management skills [11].

The effects of LMG on improving overall health systems strengthening were prominent. Primary healthcare entities with LMG intervention exposed health workers had significantly better and higher scores in management system, creating good work climate and preparedness with capacity to respond for new challenges than non-exposed facilities $(p<0.001)$. These findings correspond with the Mutale et al., (2017) report on the catalyzing effects of leadership and management trainings on health system strengthening in Zambia [3]. Similarly, 
the findings also concur with La Rue et al., (2012), who assessed and compared baseline, end-line, and post-intervention data and found an enhanced work climate through leadership development programs in Kenya [11]. Rowe et al., (2018) also confer through a systematic review that professional healthcare provider practices improved using multiple strategies rather than by a single strategy [38]. Similarly, Arinez et al., (2002) confer that good leadership and management practices improve the work climate, staff satisfaction, motivation, and performances [39].

\section{Limitations Of The Study}

Like many studies, this study has limitations. The socio-demographic characteristics of LMG exposed and non-exposed groups significantly differ before the PSM. Hence, 45 pairs of individual data were dropped for lacking similar covariate characteristics. In addition, the health service coverage reports were extracted from routine health information system database, which has known limitation in completeness. The reported average treatment effect might be affected by other covariates which are not included in our PSM model.

\section{Conclusions}

The LMG intervention had a positive and significantly increased maternal and child health service coverage in primary healthcare entities. In addition, primary healthcare entities with LMG intervention exposed health workers had significantly higher scores in terms of management systems, work climate, and readiness to face new challenges.

Therefore, the LMG interventions were found to be effective in improving maternal and child health services through enhancing the LMG competencies and skills for health workers. It is recommended that integrating LMG interventions at primary healthcare entities will accelerate the implementation of prioritized maternal and child health services and is helpful in achieving the Sustainable Development Goals as a global target.

\section{Abbreviations}

ANOVA: analysis of variance; $\mathrm{CBHI}$ : community-based health insurance; DMR: desired measurable result; FMOH: Federal Ministry of Health; LMG: leadership, management, and governance; SD: standard deviation; SNNP: Southern Nations and Nationalities of Peoples; SPSS: Statistical Package for Social Science; USAID: United States Agency for International Development; VIF: variance inflation factor; WHO: World Health Organization; ZHD: zonal health department.

\section{Declarations}

\section{Acknowledgements}

The investigators are indebted to all participants for their cooperation during data collection.

\section{Funding}

Transform Primary Health Care Project is a United States Agency for International Development (USAID) funded health program under cooperative agreement number of AID-663-A-17-00002. The program is implemented by a consortium of organizations which includes Pathfinder International, JSI Research \& Training Institute, Inc., EnCompass, Malaria Consortium, Abt Associate Inc., and Ethiopian Midwifes Association in collaboration with local Government and Non-government partners. This technical pre-post intervention report is made possible by the generous support of the American people through USAID. The authors' views expressed in this technical report do not necessarily reflect the views of USAID or the United States Government.

\section{Availability of data and materials}

The datasets used and/or analyzed during the current study are available from the corresponding author on reasonable request.

\section{Authors' contribution}

The authors of this manuscript are MDA, BFD, SAM, NT, BBT, WSA, TAB, SSB, DR, \& KE. All authors equally contributed the conception and design of the study, fieldwork, data cleaning, analysis and drafting the manuscript. All authors have read and approved the final document. MDA: the corresponding author submitted the manuscript for publication. 
The research protocol was carried out in accordance with the Declaration of Helsinki and reviewed by Amhara, Oromia, SNNP and Tigray regional state Health Bureaus Institution Review Boards and Research Ethics Committee. Written informed written consent was obtained from all research participants. The study had no known risk and no payment was made to participants.

\section{Consent for publication}

Not applicable.

\section{Competing interests}

The authors declare that they have no competing interests

\section{Authors' information}

MDA: Ph.D, Senior Health Systems Strengthening Advisor at USAID Transform: Primary Health Care, JSI Research \& Training Institute Inc., Addis Ababa, Ethiopia.

BFD: Ph.D, Deputy Chief of Party at USAID Transform: Primary Health Care, JSI Research \&Training Institute, Inc., Addis Ababa, Ethiopia.

SAM: MPH, Leadership, Management and Governance Advisor at USAID Transform: Primary Health Care, JSI Research \& Training Institute Inc., Addis Ababa, Ethiopia.

WSA: MPH, Health Information System Advisor at USAID Transform: Primary Health Care, JSI Research \& Training Institute Inc., Addis Ababa, Ethiopia.

IAB: MPH, Health Information System Advisor at USAID Transform: Primary Health Care, JSI Research \& Training Institute Inc., Addis Ababa, Ethiopia.

IAO: MPH, Director, Federal Ministry of Health, Health Extension and Primary Health Services Directorate, Addis Ababa, Ethiopia

AS: MPH, Federal Ministry of Health, Human Resource Development Directorate Addis Ababa, Ethiopia

DR: PhD, JSI Research \& Training Institute, Inc., Boston, USA.

KE: MSc, JSI Research \& Training Institute, Inc., Boston, USA.

\section{References}

[1] World Health Organization. Everybody's business-strengthening health systems to improve health outcomes: WHO's framework for action. World Health Organization; 2007.

[2] Egger D, Travis P, Dovlo D, Hawken L, World Health Organization. Strengthening management in low-income countries. World Health Organization; 2005.

[3] Mutale W, Vardoy-Mutale AT, Kachemba A, Mukendi R, Clarke K, Mulenga D. Leadership and management training as a catalyst to health system strengthening in low-income settings: Evidence from implementation of the Zambia Management and Leadership course for district health managers in Zambia. PLoS One. 2017 Jul 25;12(7):e0174536.

[4] Federal Ministry of Health of Ethiopia. Health Sector Transformation Plan. FMOH: Addis Ababa, Ethiopia;2015.

[5] Management Sciences for Health (MSH). Managers Who Lead: A Handbook for Improving Health Services. Cambridge, MA: Management Sciences for Health, 2005. www.msh.org/resource-center/managerswho-lead.cfm (accessed Jan 25, 2018).

[6] Chigudu S, Jasseh M, d'Alessandro U, Corrah T, Demba A, Balen J. The role of leadership in people-centred health systems: a subnational study in The Gambia. Health policy and planning. 2018 Jan 1;33(1):e14-25.

[7] United States of Agency for International Development: Transform: Primary Health Care Project. Theory of change in practice. Addis Ababa, Ethiopia, 2017. 
[7] United States of Agency for International Development: Transform Primary Health Care. Cooperative Agreement. Addis Ababa, Ethiopia; 2017.

[8] World Health Organization. WHO recommended interventions for improving maternal and newborn health: integrated management of pregnancy and childbirth. World Health Organization; 2009.

[9] Central statistical agency (CSA)[Ethiopia] and ICF. Ethiopia demographic and health survey, Addis Ababa, Ethiopia and Calverton, Maryland, USA; 2016.

[10] Ethiopian Public Health Institute (EPHI) [Ethiopia] and ICF. Ethiopia Mini Demographic and Health Survey 2019: Key Indicators. Rockville, Maryland, USA: EPHI and ICF; 2019.

[11] La Rue KS, Alegre JC, Murei L, Bragar J, Thatte N, Kibunga P, Cheburet S. Strengthening management and leadership practices to increase health-service delivery in Kenya: an evidence-based approach. Human resources for health. 2012 Dec 1;10(1):25.

[12] Bayou B, Hailu T, Jenberie A, Minalu Y, Tesfamichael T. Transforming primary health care unit service delivery through leadership, management and governance (LMG) training: A field action report from Ethiopia. The Ethiopian Journal of Health Development (EJHD). 2020 Feb 28;34(2).

[13] Edwards LJ, Moisés A, Nzaramba M, Cassimo A, Silva L, Mauricio J, Wester CW, Vermund SH, Moon TD. Implementation of a health management mentoring program: year-1 evaluation of its impact on health system strengthening in Zambezia Province, Mozambique. International journal of health policy and management. 2015 Jun;4(6):353.

[14] Heerdegen ACS, Aikins M, Amon S, Agyemang SA, Wyss K. Managerial capacity among district health managers and its association with district performance: a comparative descriptive study of six districts in the eastern region of Ghana. Gholipour K, editor. PLoS One. 2020;15(1):e0227974.

[15] Mansour M, Mansour JB, El Swesy AH. Scaling up proven public health interventions through a locally owned and sustained leadership development programme in rural Upper Egypt. Human Resources for Health. 2010 Dec 1;8(1):1.

[16] Creswell JW, and Plano Clark VL. Designing and conducting mixed methods research (2nd ed.). Thousand Oaks, CA: Sage; 2011.

[17] Bowling A. Research methods in health: investigating health and health services. McGraw-Hill Education (UK); 2014.

[18] Bullock EP. An Explanatory Sequential Mixed Methods Study of the School Leaders' Role in Students' Mathematics Achievement through the Lens of Complexity Theory; 2017.

[19] Khandker S, B. Koolwal G, Samad H. Handbook on impact evaluation: quantitative methods and practices. The World Bank; 2009 Oct 13.

[20] Rosenbaum PR, Rubin DB. The central role of the propensity score in observational studies for causal effects. Biometrika. 1983 Apr 1;70(1):41-55.

[21] Stuart EA. Matching methods for causal inference: a review and a look forward. Stat Sci. 2010;25(1):1-21.

[22] Federal Ministry of Health (FMOH). Leadership, Management and Governance In-Service Training Manual for Health Managers at Hospitals and Health Centers. Addis Ababa, FMOH, 2017.

[23] USAID Transform: Primary Health Care Activity. Annual Performance report of the year 2020. Addis Ababa, Ethiopia, USAID: TPHC; 2020.

[24] Ministry of Health of Ethiopia. Annual Performance Review Meeting 2018. MOH: Addis Ababa, Ethiopia, 2019.

[25] Pagano M and Gauvereau K. Principles of Biostatics. 2nd Edition, Duxbury, Pacific Grove; 2000.

[26] Daniel W. Biostatistics: A Foundation for Analysis in the Health Sciences. 9th Edition, John Wiley and Sons Inc., New York; 2009.

[27] Wiseman LM. Evaluating the effectiveness and efficiency of continuous improvement training. Oregon State University, (unpublished master's thesis); 2011. 
[28] Likert R. A Technique for the Measurement of Attitudes. Archives of Psychology, 1932:140, 1-55.

[29] Statistical Package for Social Science Inc. IBM SPSS Statistics Base 20. SPSS Inc., Chicago; 2011.

[30] Staffa SJ, Zurakowski D. Five steps to successfully implement and evaluate propensity score matching in clinical research studies. Anesthesia \& Analgesia. 2018 Oct 1;127(4):1066-73.

[31] StataCorp L. Stata treatment-effects reference manual. College Station, TX: A Stata Press Publication. 2015.

[32] Gershon RR, Stone PW, Bakken S, Larson E. Measurement of organizational culture and climate in healthcare. JONA: The Journal of Nursing Administration. 2004 Jan 1;34(1):33-40.

[33] Bland JM, Altman DG. Statistics notes: Cronbach's alpha. Bmj. 1997 Feb 22;314(7080):572.

[34] Menard S. An introduction to logistic regression diagnostics. Applied logistic regression analysis. 1995:58-79.

[35] Wells AR, Hamar B, Bradley C, Gandy WM, Harrison PL, Sidney JA, et al. Exploring robust methods for evaluating treatment and comparison groups in chronic care management programs. Popul Health Manag. 2013;16(1):35-45.

[36] Rolle IV, Zaidi I, Scharff J, Jones D, Firew A, Enquselassie F, Negash A, Deyessa N, Mitike G, Sunderland N, Nsubuga P. Leadership in strategic information (LSI) building skilled public health capacity in Ethiopia. BMC research notes. 2011 Dec 1;4(1):292.

[37] Desta, B.F., Abitew, A., Beshir, I.A. et al. Leadership, governance and management for improving district capacity and performance: the case of USAID transform: primary health care. BMC Fam Pract 21,252 (2020). https://doi.org/10.1186/s12875-020-01337-0

[38] Rowe AK, Rowe SY, Peters DH, Holloway KA, Chalker J, Ross-Degnan D. Effectiveness of strategies to improve health-care provider practices in low-income and middle-income countries: a systematic review. The Lancet Global Health. 2018 Nov 1;6(11):e1163-75.

[39] Arinez A, Bouzidi M, Koo B, Sayeed A, Serenata C, Suarez E, Sulaiman AB. Creating a Work Climate That Motivates Staff and Improves Performance. The Manager Journal. 2002;11(3).

\section{Supplementary Files}

This is a list of supplementary files associated with this preprint. Click to download.

- Addtionalfile1.docx

- Addtionalfile2.docx

- Addtionalfile3.docx

- Additionalfile4.docx

- Additonalfile5.docx 